\title{
Analgesia and sedation post-coronary artery bypass graft surgery: a review of the literature
}

This article was published in the following Dove Press journal:

Therapeutics and Clinical Risk Management

\author{
Mansour Jannati' \\ Armin Attar ${ }^{2}$ \\ 'Department of Cardiovascular Surgery, \\ Faghihi Hospital, Shiraz University of \\ Medical Sciences, Shiraz, Iran; \\ ${ }^{2}$ Cardiovascular Research Center, Shiraz \\ University of Medical Sciences, Shiraz, \\ Iran
}

\begin{abstract}
This review aimed to study the role of analgesia and sedation after coronary artery bypass graft (CABG) surgery, regarding pain management, assisted respiration, overall postoperative health care, and hospitalization. Data were collected from Pubmed, Scopus, and Cochrane databases. The following terms were used for the search: "analgesia", "sedation", "coronary artery bypass grafting", CABG", and "opioids". Articles between the years 1988 and 2018 were evaluated. Several opioid and non-opioid analgesics used to relieve surgical pain are regarded as critical risk factors for developing pulmonary and cardiovascular complications in all kinds of thoracic surgery, especially CABG procedures. Effective pain management in post-CABG patients is largely dependent on effective pain assessment, type of sedatives and analgesics administered, and evaluation of their effects on pain relief. A significant challenge is to determine adequate amounts of administered analgesics and sedatives for postoperative $\mathrm{CABG}$ patients, because patients often order more sedatives and analgesics than needed. The pain management process is deemed successful when patients feel comfortable after surgery, with no negative side effects. However, postoperative pain management patterns have not included many modern methods such as patient-controlled analgesia, and postoperative pain management drugs are still limited to a restricted range of opioid and non-opioid analgesics.
\end{abstract}

Keywords: coronary artery bypass grafting (CABG), analgesia, sedation, opioids, ICU

\section{Introduction}

Postoperative analgesia is a critical risk factor for developing pulmonary and cardiovascular complications in all kinds of thoracic surgery, especially coronary artery bypass graft (CABG) procedures. Patients with elevated pain levels fail to expand their lungs properly, which is called atelectasis. This may lead to cardiac ischemia and arrhythmia. To maintain patient general health status, well-being, relaxation, and pain management, different sedatives and analgesics are used in the intensive care unit (ICU) as a common strategy. ${ }^{1-3}$ Either analgesia or sedation is necessary to facilitate natural sleeping and assisted ventilation, and modulate mental reactions against stress (tachycardia and hypertension). ${ }^{4,5}$ These drugs have side effects that may cause different problems, in turn. previous post operation studies, evaluations, experiences or report are useful in controling the pain after operation. When a patient's real postoperative pain relief is better than anticipated, the patient is expected to be satisfied. ${ }^{6-9}$ Pain is a critical concern of postoperative CABG patients, which may result in pain being overestimated compared with the actual experience. ${ }^{10,11}$ Therefore, moderate postoperative sedative and analgesic administration may lead to patient satisfaction in those who had expected more
Department of Cardiovascular Surgery, Faghihi Hospital, Shiraz University of Medical Sciences, School of Medicine, Imam Hussain Square, Z and St., Shiraz, Iran

Email Mansour.jannati@mail.com 
pain. This may decrease the analgesic need for postoperative CABG patients and avoid overtreatment. ${ }^{12,13}$ According to previous studies, ${ }^{6-8,10-14}$ intrathecal analgesia had no effect on mortality, myocardial ischemia (MI), dysrhythmias, or endotracheal intubation time. However, it was shown to only "modestly" decrease opioid systematic administration and pain sensation, while it also increased the potential for pruritus. The results also suggest that there is no neuraxial effect on postoperative CABG mortality and MI. This may further correspond to improvement upon weaning from mechanical ventilation and earlier tracheal extubation, mitigating respiratory complications, arrhythmias, and pain sensation. ${ }^{15}$ However, postoperative $\mathrm{CABG}$ patients may gain the same clinical benefits with other methods, including fast-track anesthesia protocols, beta-blockers, antiarrhythmic medication, and non-opioid analgesic agents. The findings also suggest consistent improved postoperative pain management with no notable effect on patients' mortality and morbidity. ${ }^{15}$

This review aimed to study the role of analgesia and sedation following $\mathrm{CABG}$, regarding pain management, assisted respiration, overall postoperative health care, and hospitalization.

\section{The concepts of analgesia and sedation}

Analgesics are medications that inhibit pain sensations, whereas sedatives promote relaxation, control anxiety, and decrease the level of consciousness. However, analgesics and sedatives are often confused, because many analgesics (such as opiates) have some sedative effects as well, and an optimum level of sedatives may interrupt pain sensation or postpone pain signs. Analgesics and sedatives have distinct clinical uses based on the patient's problem, and may be wrongly prescribed in some cases. In general, analgesics are prescribed for patients who have pain and sedatives for those with anxiety and agitation. Sedative administration for pain relief may lead to overdose and a deeply comatose state (general anesthesia), and may even fail to inhibit pain sensation at the subconscious level. At the other extreme, anxiety and agitation treatment with analgesics may need higher doses because of their limited sedative effects. Pain, anxiety, dyspnea, and other forms of distress are common events in critically ill patients, who should be treated with analgesics and sedatives to improve their comfort, pain tolerance, and stress relief. Several pharmaceutical and non-pharmaceutical measures can be used to improve comfort and relaxation in these patients. ${ }^{16}$ Most ICU patients need analgesics and sedatives to control their pain, delirium, and delusional memories, and for therapeutic interventions. ${ }^{17}$

\section{Initial evaluation and management}

The evaluation of predisposing and precipitating factors for various forms of distress is a critical initial stage in ICU and post-CABG pain management. Chronic pain or arthritis, acute illness or injury, history of alcohol or substance abuse, and psychiatric illness can influence pain management and medication. Postoperative factors, ICU interventions, and drug medication can also influence post-CABG pain management. When deciding on a post-CABG pain management plan, it is critical to diagnose and control these influencing factors. It is also important to continue the patient's chronic pain medication after hospitalization; an issue which often is neglected in post-CABG patients. Antidepressants, anxiolytics, and antipsychotics are among the medical options for post-CABG patients. Overtreatment with analgesics and sedatives may cause a severe body resistance response and chronic symptoms leading to comorbid issues. For instance, sedative overmedication in post-CABG patients, with delirium, anxiety, and depression, may occur due to neglect of pre-CABG or intraCABG conditions and symptoms. Early recognition and treatment of these factors may be crucial in analgesic and sedative management and post-CABG hospitalization. ${ }^{18}$

\section{Method}

Data were collected from the PubMed, Scopus, and Cochrane databases. The following terms were used for the search: "analgesia", "sedation", "coronary artery bypass grafting", CABG", and "opioids". Articles from the years 1988-2018 were evaluated. Some of the most reputable and well-known scientific medical resources were reviewed. After a retrospective analysis, 59 clinical studies, comprising the most reliable clinical case studies and historical studies supporting an association between postoperative $\mathrm{CABG}$ and analgesic pain management and sedative treatment, were collected.

\section{Literature review}

Postoperative pain management is essential since pain is an inevitable problem involving almost all patients who undergo surgery. Numerous studies have shown that regardless of the treatment results, many patients still suffer from postoperative pain. ${ }^{19}$ 
In a study on patients undergoing $\mathrm{CABG}$, Lahtinen et al assessed patients for 4 days postoperatively, and found that $49 \%$ of patients had severe pain at rest, $78 \%$ had severe pain while coughing, and $62 \%$ had pain during movement. $^{20}$

In another study, on 705 patients undergoing cardiac surgery, pain associated with activities was measured daily until the sixth day after surgery. The most pain was seen during coughing, after movements, and during deep breathing. Even though pain scores were high in the postoperative period, patients stated mean pain scores of 4.33 while coughing and 3.09 upon deep breathing on day $6 .{ }^{21}$

Sattari et $\mathrm{al}^{22}$ studied the patient pain management process after heart surgery. This paper aimed to investigate postoperative pain control and analgesic use after heart surgery. Their sample included 120 postoperative cardiac surgery patients, with an average age of 59 years, including 81 males (67.5\%) and 39 females (32.5\%), selected using a randomized method. Among them, $69.2 \%$ had coronary artery disease and $16.7 \%$ had heartvalve problems. CABG was the major surgical event $(70.5 \%)$ and valve repair surgery was conducted in $23 \%$. Average ICU medication time was $4.78 \pm 2.7$ days, whereas the duration of intubations was $17.38 \pm 36.46$ hours. A visual analog scale (VAS) was provided for patients to score their pain levels in four different situations. Preoperative pain relief (including sedatives) was administered to $42 \%$ of patients, for whom morphine and promethazine were the main preoperative analgesia medications. Morphine (injection), petidine (injection), and NSAIDs (oral or rectal) were the preferred postoperative analgesics. The results showed that the level of reported pain was moderate in most cases, but $80 \%$ of postoperative patients reported satisfaction with their pain management. The findings also revealed that closer pain management control is needed for patients after heart surgery. The introduction of newer pain management techniques, medications, and dosages could reduce the pain and increase patient calmness and comfort.

In Elgebaly and Sabry's study, it was shown that dexmedetomidine is a safer and equally effective agent, compared to propofol, for sedation in patients admitted to the ICU after cardiovascular surgery. ${ }^{23}$

Herr et al compared dexmedetomidine-based sedation with propofol-based sedation in CABG patients. Dexmedetomidine achieved safer and more effective sedation for post-CABG patients, and significantly reduced the use of analgesics and beta-blockers. ${ }^{24}$
In another study, the early removal of chest drains on the first day after surgery was compared to removal on the third day. Patients had less pain when the chest drain was removed earlier. ${ }^{25}$

Kress et al showed that daily sedative administration could improve postoperative health care. ${ }^{26}$

\section{Pain treatment after coronary surgery}

Various analgesics and sedatives used for the treatment of pain after coronary surgery are summarized in Table 1.

\section{Opioids}

The analgesic effects of opioids are well recognized. Different opioid analgesics vary with regard to their affinity to opioid receptors, and therefore also have a variety of pharmacodynamic properties. Clinically, and especially in cardiac surgery, the most popular opioid analgesic has traditionally been morphine. Because oxycodone does not liberate histamine, it may be more cardiovascularly stable than morphine. The analgesic potency of oxycodone appears to be similar to that of morphine. ${ }^{27}$

However, clinically, they have some side effects that restrict their usefulness, particularly in high doses. The adverse effects include respiratory sedation, depression, nausea and vomiting, gastrointestinal atony, and pruritus. Opioid-induced tolerance and hyperalgesia may also limit their feasibility and dosing in clinical practice. ${ }^{28}$ Despite the well-known adverse effects of opioids, they remain the main analgesics used after cardiac surgery.

\section{Gabapentin}

Gabapentin is a 3-alkylated analog of gammaaminobutyric acid (GABA). Its probable analgesic mechanism of action is through the reduction of neurotransmitter release via a calcium-dependent mechanism or N-methyl-D-aspartate (NMDA)-mediated decrease of the glutamate-releasing mechanism. Gabapentin is particularly useful in movement-related dynamic pain, probably through its ability to inhibit central sensitization. Moreover, gabapentin is able to decrease opioid side effects, with few side effects of its own. ${ }^{29}$ Gabapentin was compared with placebo in a study on CABG patients. Morphine consumption was remarkably low in both groups. Pain scores at rest during the total 24hour study period and during coughing were lower in the gabapentin group. Nausea was decreased in gabapentin patients. ${ }^{30}$ Gabapentin can also be used as 
Table I Analgesics and sedatives for pain treatment after coronary surgery

\begin{tabular}{|c|c|c|}
\hline $\begin{array}{l}\text { Analgesics } \\
\text { and sedatives }\end{array}$ & Mechanism of action & Adverse effects \\
\hline Opioids & $\begin{array}{l}\text { Different opioid analgesics vary } \\
\text { in their affinity to opioid receptors, and therefore they have } \\
\text { a variety of pharmacodynamic properties }\end{array}$ & $\begin{array}{l}\text { Respiratory sedation, depression, nausea and vomiting, } \\
\text { gastrointestinal atony, and pruritus; opioid-induced toler- } \\
\text { ance and hyperalgesia }\end{array}$ \\
\hline Gabapentin & $\begin{array}{l}\text { Gabapentin reduces neurotransmitter release via a calcium- } \\
\text { dependent mechanism or NMDA-mediated decrease in the } \\
\text { glutamate-releasing mechanism }\end{array}$ & \\
\hline Paracetamol & $\begin{array}{l}\text { Acts via inhibiting prostaglandin synthesis, by increasing des- } \\
\text { cending serotonergic impulses that are antinococeptive, or via } \\
\text { indirectly activating cannabinoid } C B I \text { receptors }\end{array}$ & $\begin{array}{l}\text { Increased risk of gastrointestinal bleeding and a small } \\
\text { increase in systolic blood pressure }\end{array}$ \\
\hline NSAIDs & Cyclooxygenase inhibitors & $\begin{array}{l}\text { Gastrointestinal tract effects, blood pressure elevation, and } \\
\text { development of congestive heart failure }\end{array}$ \\
\hline Ketamine & Works as a non-competitive antagonist of NMDA receptors & Psychotomimetic adverse effects \\
\hline Magnesium & $\begin{array}{l}\text { Analgesic effects related to the calcium channel antagonist } \\
\text { effect and blocking the NMDA channel }\end{array}$ & Hypotension \\
\hline Propofol & & Hypotension \\
\hline Dexmedetomidine & Stimulates $\alpha 2$-adrenoreceptors in the central nervous system & Hypotension and bradycardia \\
\hline
\end{tabular}

Abbreviations: NSAIDs, nonsteroidal anti-inflammatory drugs; NMDA, N-methyl-d-aspartate.

a beneficial adjunct to opioid analgesia after cardiac surgery.

\section{Paracetamol}

Paracetamol is probably the most commonly used analgesic. It may act by preventing prostaglandin synthesis, via increasing descending serotonergic impulses, which are antinococeptive, or by secondarily activating cannabinoid CB1 receptors. Paracetamol seems to have negligent peripheral activity and it has been found that its nociceptive effect is mostly central, with almost no anti-inflammatory action in peripheral tissues. ${ }^{31}$ Paracetamol is considered as a safe analgesic; however, it carries a risk of hepatotoxicity and impaired thrombocyte function at higher doses. ${ }^{31}$ The American Society of Anesthesiologists recommends paracetamol as a component of multimodal perioperative analgesia, and it is used routinely as an analgesic adjunct after cardiac surgery. ${ }^{32}$

\section{NSAIDs}

NSAIDs are commonly used after non-cardiac surgery and are accepted as part of the routine postoperative analgesic administration. The advantages of joining NSAIDs with pain therapy include better pain relief; decreased need for opioids, with their adverse effects; and increased patient satisfaction. There have been some reports on NSAID therapy after heart surgery. In one study, indomethacin provided better pain relief than placebo after CABG surgery. Decreased opioid consumption and lower pain scores were seen at rest, but not during coughing. ${ }^{33}$ Fayaz et al described a decrease in cumulative postoperative morphine consumption, and marginally but statistically significantly lower postoperative pain scores in the diclofenac group. ${ }^{34}$ Several other NSAIDs have shown good pain relief and opioid-sparing effects after cardiac surgery; ${ }^{35,36}$ however, negative results have also found. In the study by Harney et al, the NSAID nimesulide was ineffective. There was a slight opioid-sparing effect but no changes in pain scores were seen. ${ }^{37}$

\section{Ketamine}

Ketamine has been used as a general anesthetic for many years, and is also used in subanesthetic doses use as an analgesic adjunct to postoperative opioid-based pain therapy. It works as a non-competitive antagonist of NMDA receptors, and has been shown to inhibit opioid-induced analgesic tolerance and hyperalgesia. ${ }^{38,39}$

There have been only a few studies on ketamine in cardiac surgery. In the study by Nesher et al on 58 patients 
undergoing cardiac surgery, the ketamine group showed lower pain scores and had lower morphine consumption. ${ }^{39}$ In addition, ketamine may have other useful properties in cardiac surgery. It has been demonstrated to decrease delirium after cardiopulmonary bypass at to have antidepressive and anti-inflammatory effects. ${ }^{40}$

\section{Magnesium}

Magnesium sulfate has been demonstrated to have analgesic effects related to its calcium channel antagonist effect and by blocking the NMDA channel. ${ }^{41}$ In a study in CABG patients, magnesium sulfate was administered for 3 days. Codeine or diclofenac was administered to two control groups for 3 days. The magnesium group had lower pain scores and lower morphine consumption than controls during the first 2 days after surgery. ${ }^{42}$ In a study on magnesium sulfate in CABG surgery, morphine consumption was significantly lower in both the magnesium sulfate group and placebo group. Pain scores were also lower in the magnesium group than in the placebo group. ${ }^{43}$

\section{Propofol}

Propofol is a common sedative used in the ICU for shortterm (24-hour) sedation of postoperatively ventilated patients. This drug is administered in combination with opioids for pain management to benefit from the analgesic effect at the same time. By the time, sedative overdose or irregular ventilation duration had no room in research into ICU medical/operative improvements. However, there has been increasing research into finding ways to improve and revise ICU sedation protocols. ${ }^{44}$ Clinically significant hypotension is a potential side effect of propofol in postoperative patients with unstable vital symptoms, due to its moderate vasodilatory effects. ${ }^{45,46}$ It may produce some respiratory depression, which may be amplified by opioids. ${ }^{47,48}$ Because of these side effects, propofol use is limited to pre-weaning purposes to minimize the risk of respiratory depression. Nevertheless, extremely stressful climates could impair the effectiveness of sedation. In addition, propofol use must be suspended during neurological function assessment.

\section{Dexmedetomidine}

Dexmedetomidine is a highly specific $\alpha 2$-adrenoreceptor sedative agonist, approved by the US Food and Drug Administration in 1999 as an ICU sedative agent. This drug directly stimulates $\alpha 2$-adrenoreceptors in the central nervous system, and specifically in the locus coeruleus. ${ }^{49}$
Dexmedetomidine administration mitigates sympathetic nerve activity and leads to binding of norepinephrine release. It can reduce blood pressure, similarly to clonidine, owing to its sympatholytic effects. However, this effect is significantly stronger for dexmedetomidine. ${ }^{50,51}$ Dexmedetomidine is more selective for $\alpha 2$-receptors versus $\alpha 1$-receptors, than clonidine. ${ }^{52}$ Clonidine and dexmedetomidine can both reduce opioid use. ${ }^{53-56}$ In contrast to propofol, intravenous dexmedetomidine used as a sedative showed no negative effects during weaning from the ventilator and extubation because it does not cause respiratory depression and does not decrease arterial oxygen saturation. ${ }^{57}$ The sedative/hypnotic state induced by dexmedetomidine is like a natural sleeping sensation. Although this drug is highly sedative, the patient does not lose awareness, so that he or she can answer still questions, undergo neurological tests, and react to the environment in a relaxed and comfortable state. ${ }^{58-61}$ This stimulated awakened state may disappear immediately after the drug effect is abolished and the patient returns to a sedative-induced sleep-like state. There have been several studies on dexmedetomidine's unique sedative characteristics to assess its clinical administration.

\section{Local anesthetics}

Local anesthetics are adjuvant analgesics which block sodium channels, inhibiting unexpected impulses by impaired nerves. These drugs have much higher analgesic effects when administered by local injection compared to systemic use. Local anesthetics can be administered clinically to manage acute or chronic pain, by several approaches. However, while non-opioids and opioids are administered for nociceptive pain, local anesthetics are good candidates for postoperative pain management. Treatment agents for neuropathic pain include systemic analgesics such as opioids, topical lidocaine, gabapentin, pregabalin, and some antidepressants. ${ }^{5}$ Several other drugs may also be administered for postoperative pain management.

The nervous system is dramatically affected by damage due to trauma or surgery. The impact on both the peripheral and central nervous systems is a critical decisionmaking factor in analgesic and sedative administration. Although preoperative stress management has been shown to be useful in postoperative pain management, the effects are still conflicting. ${ }^{6-8}$ 


\section{Discussion}

Postoperative pain management is a critical concern due to the highly stressful and painful nature of surgery, especially coronary artery surgery and predominantly CABG, where patient comfort and calmness play significant roles in the $\mathrm{CABG}$ procedure, regarding the patient's immune response to the new graft and the vital role of cardiac activity for all organs in the body. ${ }^{62}$ Consequently, postoperative $\mathrm{CABG}$ pain management is crucial for physicians, clinicians, and patients, because they are all fighting for the CABG patient's life after surgery. With regard to costs and complications, it is not usually possible to repeat the surgery if it fails to stabilize the patient's overall health and biometrics. ${ }^{63}$ Considering the crucial importance and vital role of postoperative pain management, there have been only a few studies in this area, thus emphasizing the immediate need for more qualitative studies exploring specific postoperative events such as pain and stress. CABG patients have been found to experience the most severe postoperative pain 1 hour after extubation, ${ }^{62-65}$ and therefore the highest doses of analgesics are prescribed and administered during this time to avoid pain. The pain level gradually decreases and reaches to its lowest level 1 hour after the patient released from the ICU and transferred to the ward.

The World Federation of Societies of Anaesthesiologists (WFSA) analgesic ladder is the main guideline for administering analgesics, including "strong opioids for moderate to severe pain, NSAIDs or acetaminophen with weak opioids for moderate pain score and NSAIDs or acetaminophen for mild pain score". ${ }^{6}$ This method is controversial, because analgesics are administered only as required by the patient, not at specific time intervals. ${ }^{66}$ This concern is more critical when it comes to strong opioids, compared with NSAIDs and acetaminophens. Misconceptions and misevaluation may inhibit clinicians in their provision of comfortable pain relief to patients. Another concern is possible addiction to strong opioids and other chemical analgesics, as well as the development of physical tolerance and side effects, which makes physicians and clinicians more prudent in their use of postoperative analgesics, especially for therapeutic use. ${ }^{67}$ For this reason, and to avoid the complications of narcotic prescription, potential abuse, and legal implications, postoperative analgesics should be limited and controlled to a certain level, and even patients will withhold adequate pain relief. ${ }^{68}$ Nevertheless, to minimize individual dependence and tolerance concerns when using opioids for postoperative CABG pain management, there are some specific principles that should be observed by clinicians. This process is particularly significant because the under-recognition of severe pain may have physiological consequences, which are elevated by the stressful reaction to surgery. The resulting endocrine, metabolic, and inflammatory events may eventually result in organ dysfunction, morbidity, hospitalization, and mortality. Pain after surgery may inhibit patients' movement, thus increasing their vulnerability to deep venous thrombosis, as well as pulmonary atelectasis, muscle wasting, hypoxemia, and urinary retention. ${ }^{66}$ Uncontrolled postoperative pain may activate the peripheral nervous system and central neuroplastic changes, leading to the development and continuation of a chronic pain status in postoperative CABG patients. $^{67}$

Patients have different responses to postoperative pain, so that opioids and other analgesics may have variable impacts on their pain, based on their individual physical and neurological characteristics. ${ }^{14,68-72}$ For this reason, the dosage of morphine and other opioids should be assessed and prescribed specifically for each patient, to provide optimal pain management. Consequently, the pain assessment process is a very important postoperative procedure, to the extent that some scholars call it the "fifth vital sign". 68 Regarding the critical importance of postoperative CABG pain management, and concerns over analgesic dependency, addiction, and tolerance, it is vital to examine and use analgesics with lower pronounced dependency or tolerance to enable more effective pain relief, and patient opioid and non-opioid analgesics need frequent assessment. In addition, there is no globally accessible and adequate oral opioid formulation (especially in developing and non-developed countries). However, regarding the nature of postoperative $\mathrm{CABG}$ pain, which reduces the reliability of opioid oral medication, the problem is less significant in this case than in the management of chronic pain for patients with cancer. Several methods have been developed for postoperative pain management based on the nature of post-surgical pain and regarding the unreliability of postoperative oral medication absorbance, which are dramatically different from chronic pain management methods. The critical concern of postoperative $\mathrm{CABG}$ pain management is to control and limit opioid use, through intraoperative magnesium sulfate administration, ${ }^{43}$ subanesthetic doses of ketamine, ${ }^{73}$ and lowering the 
patient's preoperative anxiety levels ${ }^{74}$ using non-medical approaches such as music therapy. ${ }^{75}$ One helpful concept among $C A B G$ patients is that they believe pain to be an integral part of the postoperative experience, which helps them to report satisfaction with regard to their post-surgery pain management program. ${ }^{75}$

\section{Conclusion}

Effective pain management in post-CABG patients is largely dependent on effective pain assessment, the types of sedatives and analgesics administered, and the evaluation of their effects on pain relief. The significant challenge is to determine adequate amounts of administered analgesics and sedatives for postoperative CABG patients, because patients often order more sedatives and analgesics than required. The pain management process is successful when patients feel comfortable after surgery with no negative side effects. In summary, postoperative pain management patterns have not included many modern methods such as patientcontrolled analgesia, and postoperative pain management drugs are still limited to a restricted range of opioid and nonopioid analgesics. A wide range of pain experience is still expected in postoperative CABG patients, and one way to resolve this problem would be to administer analgesics at shorter intervals to reflect their pharmacokinetics. ${ }^{22}$

\section{How to apply this knowledge to clinical practice}

The critical concern in postoperative CABG pain management is to control and limit opioid use. This could be achieved by intraoperative magnesium sulfate administration, subanesthetic doses of ketamine, and lowering patients' preoperative anxiety levels using non-medical approaches such as music therapy.

\section{Disclosure}

The authors report no conflicts of interest in this work.

\section{References}

1. Bair N, Bobek MB, Hoffman-Hogg L, Mion LC, Slomka J, Arroliga AC. Introduction of sedative, analgesic, and neuromuscular blocking agent guidelines in a medical intensive care unit: physician and nurse adherence. Crit Care Med. 2000;28(3):707-713.

2. Berger JT, Rosner F. The ethics of practice guidelines. Arch Intern Med. 1996;156(18):2051-2056. doi:10.1001/archinte.1996.00440170053006

3. Dasta JF, Fuhrman TM, McCandles C. Patterns of prescribing and administering drugs for agitation and pain in patients in a surgical intensive care unit. Crit Care Med. 1994;22(6):974-980. doi:10.1097/ 00003246-199406000-00016
4. Ostermann ME, Keenan SP, Seiferling RA, Sibbald WJ. Sedation in the intensive care unit: a systematic review. JAMA. 2000;283 (11):1451-1459. doi:10.1001/jama.283.11.1451

5. Westcott $C$. The sedation of patients in intensive care units: a nursing review. Intensive Crit Care Nurs. 1995;11(1):26-31. doi:10.1016/ S0964-3397(95)81210-5

6. Ziyaeifard M, Azarfarin R, Golzari SE. A review of current analgesic techniques in cardiac surgery. Is epidural worth it? $J$ Cardiovasc Thorac Res. 2014;6(3):133. doi:10.15171/jcvtr.2014.001

7. Freise H, Lauer S, Anthonsen S, et al. Thoracic epidural analgesia augments ileal mucosal capillary perfusion and improves survival in severe acute pancreatitis in rats. Anesthesiology. 2006;105 (2):354-359. doi:10.1097/00000542-200608000-00019

8. Faritous ZS, Aghdaie N, Yazdanian F, Azarfarin R, Dabbagh A Perioperative risk factors for prolonged mechanical ventilation and tracheostomy in women undergoing coronary artery bypass graft with cardiopulmonary bypass. Saudi J Anaesth. 2011;5(2):167-169. doi:10.4103/1658-354X.82786

9. Janati M, Mahmoodi Y, Sharifian M, et al. Prevalence and risk factors of acute renal failure after cardiac surgery in Southern Iran. Iran Red Crescent Med J. 2010;16(2):636-639.

10. Raksamani K, Wongkornrat W, Siriboon P, Pantisawat N. Pain management after cardiac surgery: are we underestimating post sternotomy pain? J Med Assoc Thai. 2013;96(7):824-828.

11. Nay PG, Elliott SM, Harrop-Griffiths AW. Postoperative pain. Expectation and experience after coronary artery bypass grafting. Anaesthesia. 1996;51(8):741-743. doi:10.1111/ana.1996.51.issue-8

12. Meehan DA, McRae ME, Rourke DA, Eisenring C, Imperial FA. Analgesic administration, pain intensity, and patient satisfaction in cardiac surgical patients. Am J Crit Care. 1995;4(6):435-442.

13. Hakim H, Samadikhah J, Alizadehasl A, Azarfarin R. Chronobiological rhythms in onset of massive pulmonary embolism in Iranian population. Middle East J Anaesthesiol. 2009;20(3):369-375.

14. Sharif F, Shoul A, Janati M, Kojuri J, Zare N. The effect of cardiac rehabilitation on anxiety and depression in patients undergoing cardiac bypass graft surgery in Iran. BMC Cardiovasc Disord. 2012;12:40. doi:10.1186/1471-2261-12-40

15. Liu SS, Block BM, Wu CL. Effects of perioperative central neuraxial analgesia on outcome after coronary artery bypass surgery: a meta-analysis. Anesthesiology. 2004;101(1):153-161. doi:10.1097/ 00000542-200407000-00024

16. Desbiens NA, Wu AW. Pain and suffering in seriously ill hospitalized patients. J Am Geriatr Soc. 2000;48(5 Suppl):S183-6.

17. Novaes MA, Knobel E, Bork AM, Pavao OF, Nogueira-Martins LA, Ferraz MB. Stressors in ICU: perception of the patient, relatives and health care team. Intensive Care Med. 1999;25(12):1421-1426.

18. Sessler CN, Grap MJ, Brophy GM. Multidisciplinary management of sedation and analgesia in critical care. Semin Respir Crit Care Med. 2001;22(2):211-226. doi:10.1055/s-2001-13834

19. Apfelbaum JL, Chen C, Mehta SS, Gan TJ. Postoperative pain experience: results from a national survey suggest postoperative pain continues to be undermanaged. Anesthesia \& Analgesia. 2003;97(2):534-540. doi:10.1213/01.ANE.0000068822.10113.9E

20. Lahtinen P, Kokki H, Hynynen M. Pain after cardiac surgery: a prospective cohort study of 1-year incidence and intensity. Anesthesiology. 2006;105 (4):794-800. doi:10.1097/00000542-200610000-00026

21. Milgrom LB, Brooks JA, Qi R, Bunnell K, Wuestfeld S, Beckman D. Pain levels experienced with activities after cardiac surgery. $\mathrm{Am}$ $J$ Crit Care. 2004;13(2):116-125.

22. Sattari M, Baghdadchi ME, Kheyri M, Khakzadi H, Ozar Mashayekhi S. Study of patient pain management after heart surgery. Adv Pharm Bull. 2013;3(2):373-377.

23. Elgebaly AS, Sabry M. Sedation effects by dexmedetomidine versus propofol in decreasing duration of mechanical ventilation after open heart surgery. Ann Card Anaesth. 2018;21(3):235-242. doi:10.4103/ aca.ACA_174_17 
24. Herr DL, Sum-Ping ST, England M. ICU sedation after coronary artery bypass graft surgery: dexmedetomidine-based versus propofol-based sedation regimens. J Cardiothorac Vasc Anesth. 2003;17(5):576-584. doi:10.1016/S1053-0770(03)00200-3

25. Mueller XM, Tinguely F, Tevaearai HT, Ravussin P, Stumpe F, von Segesser LK. Impact of duration of chest tube drainage on pain after cardiac surgery. Eur J Cardiothorac Surg. 2000;18(5):570-574.

26. Kress JP, Christenson J, Pohlman AS, Linkin DR, Hall JB. Outcomes of critically ill cancer patients in a university hospital setting. $\mathrm{Am}$ J Respir Crit Care Med. 1999;160(6):1957-1961. doi:10.1164/ ajrccm.160.6.9812055

27. Poyhia R. Opioids in anaesthesia: a questionnaire survey in Finland. Eur J Anaesthesiol. 1994;11(3):221-230.

28. Crawford MW, Hickey C, Zaarour C, Howard A, Naser B. Development of acute opioid tolerance during infusion of remifentanil for pediatric scoliosis surgery. Anesth Analg. 2006;102 (6):1662-1667. doi:10.1213/01.ane.0000216036.95705.c2

29. Zhang J, Ho KY, Wang Y. Efficacy of pregabalin in acute postoperative pain: a meta-analysis. $B r \quad J$ Anaesth. 2011;106 (4):454-462. doi:10.1093/bja/aer027

30. Menda F, Koner O, Sayin M, Ergenoglu M, Kucukaksu S, Aykac B. Effects of single-dose gabapentin on postoperative pain and morphine consumption after cardiac surgery. J Cardiothorac Vasc Anesth. 2010;24(5):808-813. doi:10.1053/j.jvca.2009.10.023

31. Smith HS. Perioperative intravenous acetaminophen and NSAIDs. Pain Med. 2011;12(6):961-981. doi:10.1111/j.1526-4637.2011.01141.x

32. American Society of Anesthesiologists Task Force on Acute Pain Management. Practice guidelines for acute pain management in the perioperative setting: an updated report by the American Society of Anesthesiologists Task Force on Acute Pain Management. Anesthesiology. 2004;100(6):1573-1581.

33. Rapanos T, Murphy P, Szalai JP, Burlacoff L, Lam-McCulloch J, Kay J. Rectal indomethacin reduces postoperative pain and morphine use after cardiac surgery. Can J Anaesth. 1999;46(8):725-730. doi:10.1007/BF03013906

34. Fayaz MK, Abel RJ, Pugh SC, Hall JE, Djaiani G, Mecklenburgh JS. Opioid-sparing effects of diclofenac and paracetamol lead to improved outcomes after cardiac surgery. $J$ Cardiothorac Vasc Anesth. 2004;18(6):742-747. doi:10.1053/j.jvca.2004.08.012

35. Khalil MW, Chaterjee A, Macbryde G, Sarkar PK, Marks RR. Single dose parecoxib significantly improves ventilatory function in early extubation coronary artery bypass surgery: a prospective randomized double blind placebo controlled trial. Br J Anaesth. 2006;96 (2):171-178. doi:10.1093/bja/aei298

36. Kulik A, Ruel M, Bourke ME, et al. Postoperative naproxen after coronary artery bypass surgery: a double-blind randomized controlled trial. Eur J Cardiothorac Surg. 2004;26(4):694-700. doi:10.1016/j. ejcts.2004.07.004

37. Harney DF, Dooley M, Harhen B, et al. Nimesulide $90 \mathrm{mg}$ orally twice daily does not influence postoperative morphine requirements after major chest surgery. Anesth Analg. 2008;106(1):294-300. table of contents. doi:10.1213/01.ane.0000289528.87796.0b

38. Kissin I, Brown PT, Robinson CA, Bradley EL Jr. Acute tolerance in morphine analgesia: continuous infusion and single injection in rats. Anesthesiology. 1991;74(1):166-171. doi:10.1097/00000542199101000-00025

39. Nesher N, Serovian I, Marouani N, Chazan S, Weinbroum AA. Ketamine spares morphine consumption after transthoracic lung and heart surgery without adverse hemodynamic effects. Pharmacol Res.2008 Jul;58(1):38-44. doi:10.1016/j.phrs.2008.06.003

40. Welters ID, Feurer MK, Preiss V, et al. Continuous S-(+)-ketamine administration during elective coronary artery bypass graft surgery attenuates pro-inflammatory cytokine response during and after cardiopulmonary bypass. Br J Anaesth. 2011;106(2):172-179. doi:10.1093/ bja/aeq341
41. Ryu JH, Kang MH, Park KS, Do SH. Effects of magnesium sulphate on intraoperative anaesthetic requirements and postoperative analgesia in gynaecology patients receiving total intravenous anaesthesia. Br J Anaesth. 2008;100(3):397-403. doi:10.1093/bja/ aem 407

42. Bolcal C, Iyem H, Sargin M, et al. Comparison of magnesium sulfate with opioid and NSAIDs on postoperative pain management after coronary artery bypass surgery. J Cardiothorac Vasc Anesth. 2005;19 (6):714-718. doi:10.1053/j.jvca.2005.08.010

43. Ferasatkish R, Dabbagh A, Alavi M, et al. Effect of magnesium sulfate on extubation time and acute pain in coronary artery bypass surgery. Acta Anaesthesiol Scand. 2008;52(10):1348-1352. doi:10.1111/j.1399-6576.2008.01783.x

44. Kollef MH, Levy NT, Ahrens TS, Schaiff R, Prentice D, Sherman G. The use of continuous i.v. sedation is associated with prolongation of mechanical ventilation. Chest. 1998;114(2):541-548.

45. Claeys MA, Gepts E, Camu F. Haemodynamic changes during anaesthesia induced and maintained with propofol. Br J Anaesth. 1988;60 (1):3-9. doi:10.1093/bja/60.1.3

46. Aitkenhead AR, Pepperman ML, Willatts SM, et al. Comparison of propofol and midazolam for sedation in critically ill patients. Lancet. 1989;2(8665):704-709.

47. Barr J, Donner A. Optimal intravenous dosing strategies for sedatives and analgesics in the intensive care unit. Crit Care Clin. 1995;11 (4):827-847. doi:10.1016/S0749-0704(18)30041-1

48. Leino K, Mildh L, Lertola K, Seppala T, Kirvela O. Time course of changes in breathing pattern in morphine- and oxycodone-induced respiratory depression. Anaesthesia. 1999;54(9):835-840. doi:10.1046/j.1365-2044.1999.00946.x

49. Maze M, Scheinin M. Molecular pharmacology of $\alpha 2$-adrenergic receptors. Anesth Pharmacol Rev. 1993;1:233-237.

50. Testa LD, Tobias JD. Pharmacologic drugs for controlled hypotension. J Clin Anesth. 1995;7(4):326-337. doi:10.1016/09528180(95)00010-F

51. Zhang YH, Zhu J, Song YC. Suppressing sympathetic activation with clonidine on ventricular arrhythmias in congestive heart failure. Int $J$ Cardiol. 1998;65(3):233-238. doi:10.1016/S0167-5273(98) 00127-2

52. Virtanen R, Savola JM, Saano V, Nyman L. Characterization of the selectivity, specificity and potency of medetomidine as an alpha 2-adrenoceptor agonist. Eur J Pharmacol. 1988;150(1-2):9-14. doi:10.1016/0014-2999(88)90744-3

53. Venn RM, Bradshaw CJ, Spencer R, et al. Preliminary UK experience of dexmedetomidine, a novel agent for postoperative sedation in the intensive care unit. Anaesthesia. 1999;54(12):1136-1142. doi:10.1046/j.1365-2044.1999.01114.x

54. Talke P, Maze M, Karhuvaara S, editors. Alpha2-agonist, dexmedetomidine, in anesthesia and analgesia. 11th World Congress of Anaesthesiologists; 1996; Sydney, Australia Anesth Analg.

55. Hall JE, Uhrich TD, Barney JA, Arain SR, Ebert TJ. Sedative, amnestic, and analgesic properties of small-dose dexmedetomidine infusions. Anesth Analg. 2000;90(3):699-705. doi:10.1097/ 00000539-200003000-00035

56. Kamibayashi T, Maze M. Clinical uses of alpha2 -adrenergic agonists. Anesthesiology. 2000;93(5):1345-1349.

57. Venn RM, Hell J, Grounds RM. Respiratory effects of dexmedetomidine in the surgical patient requiring intensive care. Crit Care. 2000;4(5):302-308. doi:10.1186/cc712

58. Bradley C. Dexmedetomidine-a novel sedative for postoperative sedation. Intensive Crit Care Nurs. 2000;16(5):328-329. doi:10.1054/iccn.2000.1529

59. Colombo JA, Lewis KS, Rothenberg DM, Tuman KJ, editors. Dexmedetomidine as monotherapy for sedation after cardiac surgery in the intensive care unit. ASA Annual Meeting Abstracts; new Orleans: 2001. 
60. Ebert TJ, Hall JE, Barney JA, Uhrich TD, Colinco MD. The effects of increasing plasma concentrations of dexmedetomidine in humans. Anesthesiology. 2000;93(2):382-394.

61. Guo T-Z, Buttermann AE, Jiang J-Y, Maze M. Dexmedetomidine injection into the locus coeruleus produces analgesia. Anesthesiology 1996; 84:873-881.

62. The management of postoperative pain, update in anaesthesia. World Federation Soc Anaesthesiol. 2011;Ar. 2(7):88-92.

63. Leegaard M, Fagermoen MS. Patients' key experiences after coronary artery bypass grafting: a synthesis of qualitative studies. Scand J Caring Sci. 2008;22(4):616-628. doi:10.1111/j.1471-6712.2007.00556.x

64. Hamilton GR, Baskett TF. In the arms of Morpheus the development of morphine for postoperative pain relief. Can J Anaesth. 2000;47 (4):367-374.

65. WHO. Essential medicines: WHO model list; 2005 14. Available from: http://whqlibdoc.who.int/hq/2005/a87017_eng.pdf.Accessed March 1, 2017.

66. Loach A.The Management of Postoperative Pain Orthopaedic Anaesthesia. London: Edward Arnold; 1994:65.

67. Perkins FM, Kehlet H. Chronic pain as an outcome of surgery. A review of predictive factors. Anesthesiology. 2000;93(4):1123-1133.

68. Sattari M, Routledge P, Mashayekhi S. The influence of active transport systems on morphine -6-glucuronide transport in MDCKII and MDCK-PGP cells. Daru. 2011;19(6):412-416.

69. Mashayekhi SO, Sattari MR, Routledge PA. Evidence of active transport involvement in morphine transport via MDCKII and MDCK-PGP cell lines. Res Pharm Sci. 2010;5(2):99-106.
70. Mashayekhi SO, Ghandforoush-Sattari M, Buss DC, Routledge PA, Hain RD. Impact of anti-cancer drugs and other determinants on serum protein binding of morphine 6-glucuronide. Daru. 2010;18(2):107-113.

71. Mashayekhi SO, Hain RD, Buss DC, Routledge PA. Morphine in children with cancer: impact of age, chemotherapy and other factors on protein binding. J Pain Palliat Care Pharmacother. 2007;21(4):5-12.

72. Kojuri J, Mahmoodi Y, Jannati M, Shafa M, Ghazinoor M, Sharifkazemi MB. Ability of amiodarone and propranolol alone or in combination to prevent post-coronary bypass atrial fibrillation. Cardiovasc Ther. 2009;27(4):253-258. doi:10.1111/j.1755 5922.2009.00100.x

73. Nesher N, Ekstein MP, Paz Y, Marouani N, Chazan S, Weinbroum AA. Morphine with adjuvant ketamine vs higher dose of morphine alone for immediate postthoracotomy analgesia. Chest. 2009;136(1):245-252. doi:10.1378/chest.08-0246

74. Woodhead J, Harding SA, Simmonds M, Dee S, McBride-Henry K. Premedication for cardiac catheterization and percutaneous coronary intervention: does it increase vascular access site complications? J Cardiovasc Nurs. 2007;22(6):466-471. doi:10.1097/01. JCN.0000297386.14002.f2

75. Ebneshahidi A, Mohseni M. The effect of patient-selected music on early postoperative pain, anxiety, and hemodynamic profile in cesarean section surgery. J Altern Complement Med. 2008;14(7):827-831. doi:10.1089/acm.2007.0752

76. Boldt J, Lenz M, Kumle B, Papsdorf M. Volume replacement strategies on intensive care units: results from a postal survey. Intensive Care Med. 1998;24(2):147-151.
Therapeutics and Clinical Risk Management

\section{Publish your work in this journal}

Therapeutics and Clinical Risk Management is an international, peerreviewed journal of clinical therapeutics and risk management, focusing on concise rapid reporting of clinical studies in all therapeutic areas, outcomes, safety, and programs for the effective, safe, and sustained use of medicines. This journal is indexed on PubMed Central, CAS

\section{Dovepress}

EMBase, Scopus and the Elsevier Bibliographic databases. The manuscript management system is completely online and includes a very quick and fair peer-review system, which is all easy to use. Visit http://www.dovepress.com/testimonials.php to read real quotes from published authors. 